\title{
Conditions of Geotechnological Feasibility of Mineral Reserves
}

\author{
Jacek Engel ${ }^{1}$, Radim Rybar $^{1, *}$, and Viktor Shalamanov ${ }^{2}$ \\ ${ }^{1}$ Technical University of Kosice, Faculty of Mining, Ecology, Process Control and Geotechnologies, \\ Letná 9, 04200 Kosice, Slovak Republic \\ ${ }^{2}$ T.F. Gorbachev Kuzbass State Technical University, 65000028 Vesennya st., Kemerovo, Russia
}

\begin{abstract}
The evaluation of a deposit and mining project is a continuous process rather than a single act. Changes in budget, evaluation criteria, or in the area of costs and incomes may change results valid up to now and the views on using a deposit. Geological quantities are measurable with the help of geological conclusions and engineering calculations. Raw material reserves and their quality are defined as a substance that can be recovered with profit through current technologies and prices. This definition can result in two misunderstandings: geological reserves and the quality of raw materials are understood as variables not connected with mining activities. However, the quantity and quality of remaining reserves depends on changes in our geological knowledge, changing economic conditions, as well as on the exhaustion of reserves. The quantity of reserves and value of the cut-off grade depends not only on geological factors but also upon the methods of deposit extraction, costs and prices.
\end{abstract}

\section{Introductions}

The estimation of quantity and quality of reconnaissance resources is based on an analogy with other similar areas explored in detail, in which deposits of the identical genetic and formation type have been verified.

The new classification of reserves and resources (ECE - UN) proposes to divide the degree of exploration depending on the stage of deposit geological work to [1-2]:

1. Detailed exploration.

2. General exploration.

3. Prospecting.

4. Reconnaissance.

The new system proposes to list the degree of exploration to the last, third place, after classification of the economic viability category and classification stage evaluation feasibility.

Deposits of various origin, different geological structure and variability require different density of the exploration network for a certain degree of exploration. The exploration network density is conditioned by [3-4]:

1. The required accuracy of exploration (required category of reserves).

* Corresponding author: radim.rybar@tuke.sk 
2. The character of the explored deposit.

\section{Materials and Methods}

In accordance with V.M. Krejter (1961) the exploration network density is understood as a deposit area which belongs to one exploration corridor [5]:

$$
S_{o}=\frac{S}{n}
$$

where: $\mathrm{S}$ - is the area of the ore body (deposit),

$\mathrm{n}$ - is a number of exploration works that intersect the ore body (deposit).

In exploration practice the exploration network density is expressed either by the size of the area $\mathrm{S}_{\mathrm{o}}$ or by the distance between exploration works.

The main factor, which determines the exploration network density is the degree of variability of individual deposit parameters. The more variable the deposit, the higher the density of the exploration network required. In some cases, complicated differential equations can be used for evaluation [6]. Moreover, precise evaluation of the mineral deposits is required for planning of the mining works and calculated possible coal output [7-9].

The classification of exploration stages in accordance with the relative accuracy $p$ of calculated reserves and their quality has been proposed as follows:
- $\mathrm{p}<10 \%$
(for detailed exploration);
-p $10-25 \%$
(for general exploration);
-p $25-80 \%$
(for prospecting);
$\cdot p>80 \%$
(for reconnaissance).

\section{Results and Discussion}

The definition of dependencies between reserves of the deposit $Z$, average grade $x$ and cut off grade $x_{o}$ is of crucial importance for the optimum classification of proved reserves to balancing (economic) reserves and non-balancing (potentially economic) reserves. As a rule, the dependencies between $\mathrm{Z}, \mathrm{x}$ and $\mathrm{x}_{0}$ are obtained by means of alternative calculations of reserves at various cut off grades $x_{0}$. In the majority of mineral deposits the quantity of geological reserves $Z$ and their average grade $x$ depend on the accepted cut off grade $x_{o}$ value. When the cut off grade $x_{o}$ values are low, the estimation (calculation) of reserves results in a large quantity of geological reserves $Z$ with a low average grade $x$. With the increase of the cut off grade $x_{o}$ the quantity of geological reserves $Z$ decreases and the average grade $x$ increases.

Depending on the variability of mineralization and industrial component distribution type (lognormal, normal, left asymmetric, right asymmetric, bimodal, complex, etc.) the curve of reserve dependency $Z$ on the cut off grade $x_{o}$ also changes (Fig. 1). 


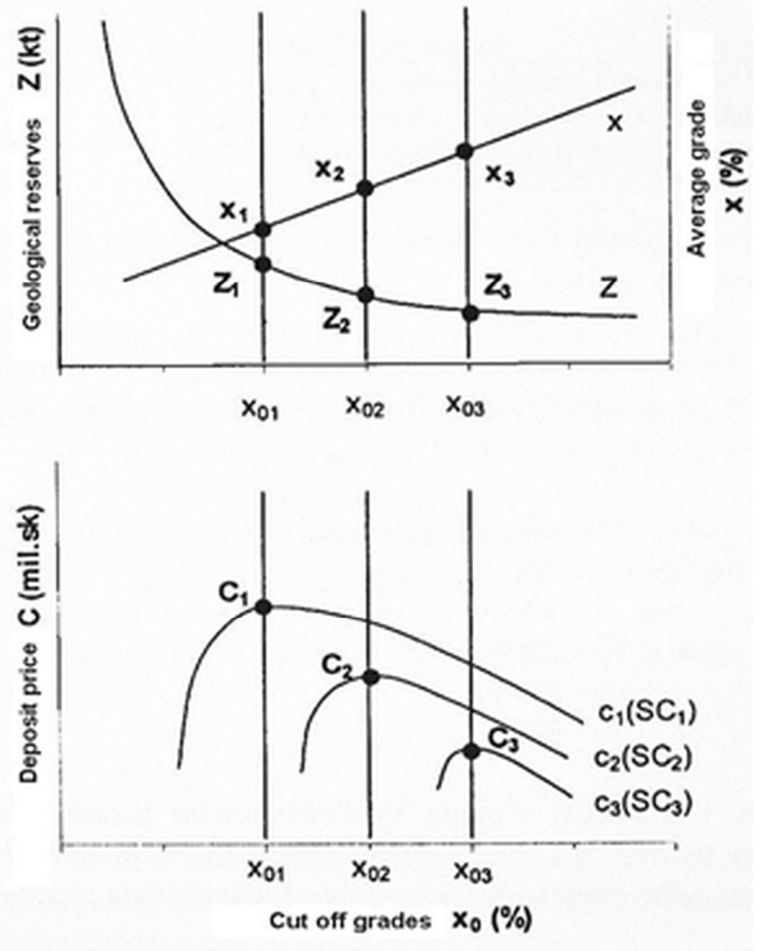

Fig. 1. Dependency between maximum deposit price $(C)$ and geological deposit parameters $Z, x, x 0$ at changed prices of mineral commodities (SC).

From the above stated it results, that each mineral deposit, being a unique natural object, has its specific properties, which it is possible to express by means of dependencies $Z, x_{1} x_{0}$ which can be graphically and mathematically described on the basis of alternative estimations (calculations) of reserves with various cut off grades of industrial components at each studied deposit.

The suitability of this procedure which defines dependencies between $\mathrm{Z}, \mathrm{x}$ and $\mathrm{x}_{\mathrm{o}}$ results from the need to define contours of balancing and non-balancing reserves and also from the possibility to use this method for the definition of optimum $\mathrm{Z}, \mathrm{x}$ and $\mathrm{x}_{0}$, which correspond to the maximum deposit price at variable economic, technical and technological parameters (price, production costs, contamination, recovery, yield, etc.). The relationship between the deposit price and "static" geological-deposit parameters $\left(\mathrm{Z}, \mathrm{x}, \mathrm{x}_{\mathrm{o}}\right)$ is illustrated in Fig. 2. 


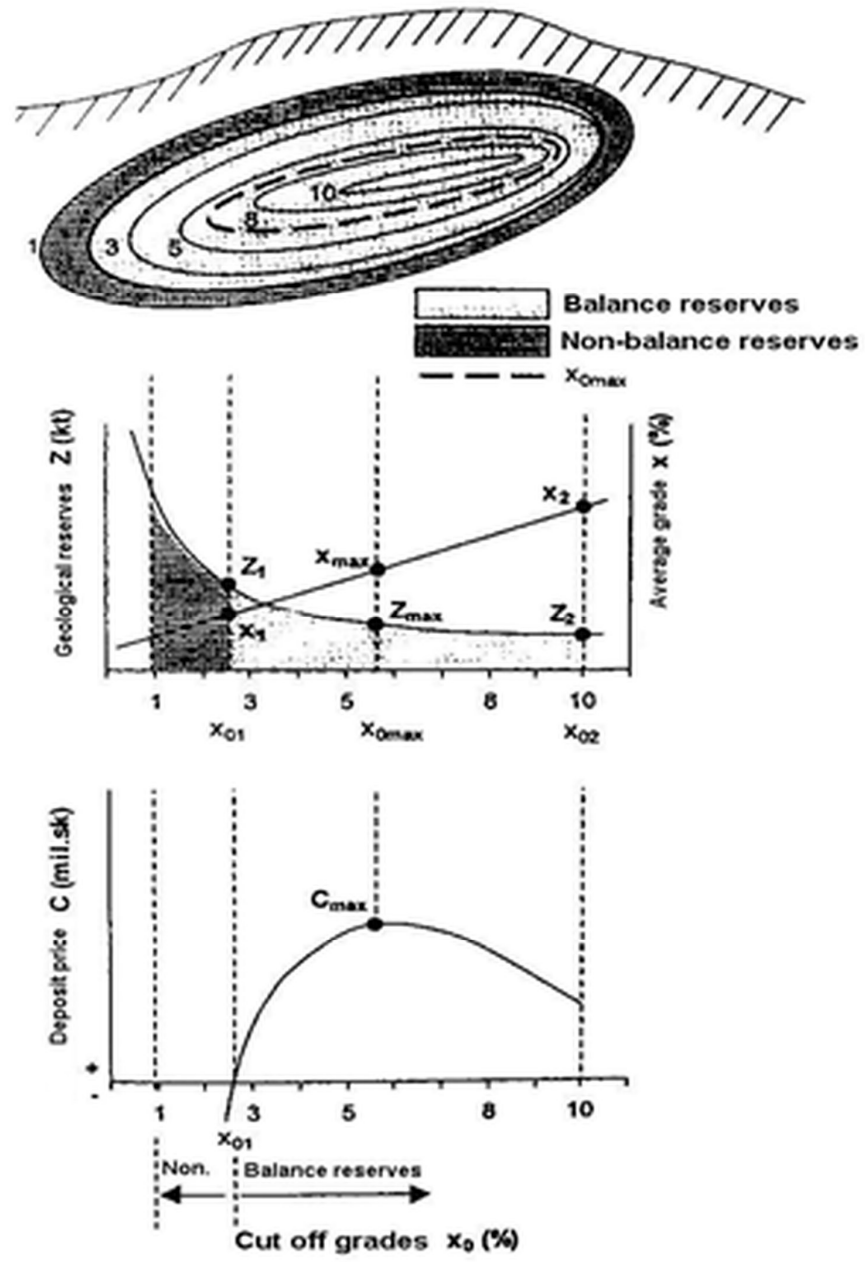

Fig. 2. Methodology of defining balancing and non-balancing reserves for state owned deposits.

From Fig. 2 it results that with the growth of global prices of mineral commodities $\left(\mathrm{SC}_{1}\right.$ $\geq \mathrm{SC}_{2} \geq \mathrm{SC}_{3}$ ) and constant production costs, technical and technological parameters, not only the increase of deposit prices $\left(\mathrm{C}_{1} \geq \mathrm{C}_{2} \geq \mathrm{C}_{3}\right)$, but simultaneously the change of optimum geological-deposit parameters $\mathrm{Z}, \mathrm{x}$ a $\mathrm{x}_{0}$ corresponding to the maximum deposit prices occur: - at the world price $\mathrm{SC}_{1}$ reserves of the deposit $\mathrm{Z}_{1}$ with the average grade $\mathrm{x}_{1}$ above the cut off grade $\mathrm{x}_{01}$ correspond to the maximum deposit price $\mathrm{C}_{1}$;

- at the world price $\mathrm{SC}_{2}$ reserves of the deposit $\mathrm{Z}_{2}$ with the average grade $\mathrm{x}_{2}$ above the cut off grade $\mathrm{x}_{02}$ correspond to the maximum deposit price $\mathrm{C}_{2}$;

- after further drops in the global price to the level $\mathrm{SC}_{3}$, reserves of the deposit $\mathrm{Z}_{3}$ with the average grade $\mathrm{x}_{3}$ above the cut off grade $\mathrm{x}_{03}$ corresponding to the maximum deposit price $\mathrm{C}_{3}$; - a further drop in the global prices of the given commodity would result in a negative value of the deposit price, i.e., no reserves would be listed as economic, and all deposit reserves would be classified only as potentially economic.

Similar dependencies between the deposit price and "static" geological-deposit characteristics $\left(\mathrm{Z}, \mathrm{x}, \mathrm{x}_{\mathrm{o}}\right)$ also apply in cases of more significant changes in production costs and technical and technological parameters. From the above it can be assumed that the 
deposit price $C$ (economic value of its proved reserves) depends not only on the price of raw materials $c$, production costs $n$ and technical and technological parameters $t p$, but also on geological-deposit parameters $\left(\mathrm{Z}, \mathrm{x}, \mathrm{x}_{0}\right)$, which principally affect "dynamic" economic and technical and technological parameter (2).

$$
\mathrm{C} \rightarrow \mathrm{f}\left(\mathrm{Z}, \mathrm{x}, \mathrm{x}_{0}, \mathrm{n}, \mathrm{c}, \mathrm{tp}\right)
$$

From mutual dependencies between the so called "static" (geological-deposit) and "dynamic" (technical, technological and economic) parameter mineral deposits it results that:

1. Only an accurately specified quantity of reserves, defined by means of the cut off grade $x_{o}$ value, average grade $x$ value and geological reserves $Z$ correspond to the maximum deposit price at a constant price of raw materials, constant production costs and technical and technological parameters. Significant changes in raw material prices, production costs and technical and technological parameters result in changes of cut off grades $x_{o}$, average grades $x$ and geological reserves $Z$ that define the maximum deposit price.

2 . With a certain ratio between raw material prices and production costs $(n$ and $c)$ the balancing (economic) reserves are "lost" $\left(Z_{B}=0\right)$, and only non-balancing reserves (potentially economic resources), the quantity $\left(Z_{N}\right)$ and average grade $\left(\mathrm{x}_{\mathrm{N}}\right)$ of which correspond to reserves above the contour of the cut off grade for non-balancing reserves $\left(\mathrm{x}_{\mathrm{ON}}\right)$, remain in the deposit.

Despite the fact that mineral deposits have different origins, age, morphology, composition, etc., the use of the above stated methodology for the economic viability evaluation of reserves and resources (balancing - non-balancing) is likely to become generally applicable for the majority of mineral deposits, with certain modifications for various morphological and geological-technological types.

In accordance with our valid legal standards balancing reserves are reserves that are usable at present, and meet current technical, technological and economic conditions of the use of the state owned deposit or its part. Non-balancing reserves are reserves unusable at present, however, with regard to the technical, technological and economic development, their use in the future is assumed [10].

Internationally, balancing reserves are reserves that ensure profitable extraction at defined investment assumptions with a reasonable degree of assurance. From this definition it results that these are reserves that must ensure profitable extraction. The issue that arises is the definition of the optimum profit-cost ratio (profitability), at which contours of balancing reserves are defined. The previous chapter implies that in some deposits with a high average grade (with a high value of differential mining rent), it is possible to also define contours of reserves with a value lower than $\mathrm{x}_{\mathrm{omax}}$ that meet the standards of balancing reserves along with contours of reserves defining the maximum deposit price (cut off grade $\mathrm{x}_{\mathrm{omax}}$.). For example, it is possible to define contours with the following cut off grade:

- $\mathrm{x}_{01}$, which ensures profitability $\mathrm{R}=10 \%$;

- $\mathrm{x}_{02}$, which ensures profitability $\mathrm{R}=20 \%$;

- $\mathrm{x}_{03}$, which ensures profitability $\mathrm{R}=30 \%$.

Current understanding of "conditions for feasibility of reserves" (CFR) (conditions), along with the requirement to direct geological work during the prospecting stage in accordance with conditions for feasibility of expected reserves in a state owned deposit set in advance, leads to disputable methodological procedures, which in some cases may have a negative impact on the deposit evaluation.

First of all, each deposit is understood as a unique object with a natural accumulation of industrially usable minerals, for which it is neither possible nor reasonable to define the CFR, which serves for the division of reserves to balancing and non-balancing, in advance. In advance, e.g. before starting the prospecting stage it is only possible to state generally that 
the goal is to search for and verify the biggest and highest grade deposit, e.g. of gold, or other minerals. Parameters (like reserves, quality, etc.) of a deposit, which is verified after completing work at the given stage, e.g. prospecting stages are not known in advance, and it is possible to start the economic evaluation of the deposit only subsequently, when its "static" geological-deposit parameter $\left(\mathrm{Z}, \mathrm{x}, \mathrm{x}_{\mathrm{o}}\right)$ as well as other mining, technical, technological, environmental and other parameters are defined in alternative calculations.

The philosophy of the CFR set in advance does not consider the existence of dependencies between deposit price and "static" geological-deposit parameters, hence it does not allow the definition of the optimum contour of balancing reserves $x_{B}, x_{B m a x}$, as stated above.

The second significant drawback in the methodology of defining the CFR for ore and selected non-metallic raw materials is the defining of one value of the "marginal sample" (cut off grade $\mathrm{x}_{0}$ ) for balancing and non-balancing reserves of the deposit (as a rule in accordance with a $50 \%$ value of treatment costs). This approach results in the increase of the reserve quantity in many ore deposits, however their average grade decreases. Naturally this fact has a negative impact on the deposit price and the ratio between balancing and non-balancing reserves. As reasoned in the previous chapters, and as also results from the definition of balancing and non-balancing reserves, cut off grades should be defined individually for balancing non-balancing reserves $x_{O B}, x_{O N}$.

The third drawback of methodologies of defining the CFR for ore and some non-metallic deposits that are frequently used nowadays consists in the possibility of assigning "low grade blocks of reserves" to higher grade blocks of reserves up to the value of the defined minimal average grade for balancing reserves of the entire deposit. This can eventually reduce the deposit price by reducing the average grade of balancing reserves $x_{B}$.

In case of some non-metallic raw materials, the balancing of which is evaluated in accordance with general conditions of non-metallic minerals in the prospecting stage, it is worth emphasising that in the case of absence of economic (cost and price) CFR parameters, the objective definition of balancing and non-balancing reserves is purely illusory.

Also the requirements of these conditions with regard to the minimum quantity of balancing and non-balancing reserves can be considered economically proofless. As in the case of many non-metallic raw materials the changes of technological requirements have also been made, we consider further application of these conditions for the evaluation of the balancing and non-balancing of proved reserves unsuitable.

The evaluation of the balancing and non-balancing state of proved reserves of brown coal and lignite having completed the stage of prospecting is problematic, similarly to the group of non-metallic raw materials. Doubts on the objectiveness of evaluating the coal deposit reserves balancing is caused by the absence of economic parameters (price, production costs) in the conditions.

Also in the case of non-metallic raw material and coal deposits it is possible to consider the CFR (conditions) only as a set of geological-deposit, technological and technical requirements, which when lacking economic requirements and the optimum methodological approach documented in the previous chapters, enable neither the objective classification of proved reserves to balancing and non-balancing nor the quantification of the deposit price.

\section{Conclusion}

The economic evaluation of projects respects recent trends in adjudicating the economic effectiveness of projects developed in the most advanced economic systems and at the same time adapts it to particular project conditions. This approach respects not only economic but also mining, geological and environmental factors and their effects on the project results, thus giving a view of the complex interrelations of all project variables. The financial analysis is 
also suitable due to the reason that financial experts, based on the study, have the possibility to understand whether the project is profitable and what its main risks and advantages are.

\section{References}

1. H. Wackernagel, Multivaiate geostatistics (Springer Verlag. Berlin, 1995)

2. T.A. O'Hara, S.C. Suboleski, Cost and Cost Estimation. SME Mining Engineering Handbook (Springer Verlag. Berlin, 1992)

3. M. Armstrong, P.A. Dowd, Geostatistical simulations (Kluwer academic publishers, London, 1994)

4. H.A. Fraser, D.S. Richard, Economics of Worldwide Petroleum Production (Oil \& Gas Consultants International, Inc., Oklahoma, 1993)

5. Th.F. Torries, Evaluating Mineral Projects: Applications and Misconceptions (Society for Mining, Metallurgy and Exploration, Littleton, 1997)

6. D.Yu. Sirota, M.A. Babushkin, Journal of Mining and Geotechnical Engineering, 2, 6574 (2018) DOI: 10.26730/2618-7434-2018-2-65-74

7. V.L. Martyanov, Journal of Mining and Geotechnical Engineering, 1, 35-41 (2018) DOI: 10.26730/2618-7434-2018-1-35-41

8. V.A. Ermolaev, A.V. Selyukov, Journal of Mining and Geotechnical Engineering, 2, 5064 (2018) DOI: 10.26730/2618-7434-2018-2-50-64

9. A.V. Katsubin, E.V. Makridin, Journal of Mining and Geotechnical Engineering, 1, 8188 (2018) DOI: 10.26730/2618-7434-2018-1-81-88

10. Cavender, Determination of the optimum lifetime of a mining project using discounted cash-flow and option pricing techniques (Mining Engineering, New York, 1992) 